\title{
COMPRESSION SET AND DAMPING PROPERTIES OF OIL- EXTENDED ELASTOMERS FOR SEALANTS PRODUCTION
}

\author{
VOJISLAV JOVANOVIĆ ${ }^{*}$, JAROSLAVA BUDINSKI-SIMENDIĆ ${ }^{2}$ LJILJANA \\ KORUGUC-KARASZ ${ }^{3}$, AYSE AROGUZ ${ }^{4}$, JELENA MILIĆ ${ }^{2}$, NEVENA VUKIĆ ${ }^{2}$, GORDANA \\ MARKOVIĆ ${ }^{5}$, PERO DUGIĆ ${ }^{6}$
}

\author{
${ }^{1}$ Faculty of Natural Science and Mathematics, University of Priština, Kosovska Mitrovica, Serbia, \\ ${ }^{2}$ Faculty of Technology, University of Novi Sad, Novi Sad, Serbia, \\ ${ }^{3}$ University of Massachusetts, Amherst, USA \\ ${ }^{4}$ University of Istanbul, Engineering Faculty, Istanbul, Turkey \\ ${ }^{5}$ Tigar, Pirot, Serbia \\ ${ }^{6}$ Faculty of Technology, University of Banja Luka, Banja Luka, Bosnia and Herzegovina
}

\begin{abstract}
Damping materials have been widely used in the vibration and noise control to reduce their harmful consequences in different areas such as their application in the drilling equipment, aerospace and naval vessels, transportation vehicles, bridges and high buildings. Because of severe environmental standards, the oil fabrication is developing synthetic environmentally friendly drilling fluids. For a vehicle, applications are produced: the outer and inner beltline seals and the glass run channel. The compression set is the important characteristic of elastomeric sealing materials as spontaneous stress release during applica tion due to the internal pressure or external forces variations. The temperature- and frequency-insensitive damping are of significance for industrial uses. Elastomeric hybrid materials based on terpolymers as network precursor are very common for sealants fabrication. The focus of this work was to prepare oil-extended elastomeric hybrid materials based on ethylenepropylene-diene monomer rubber (EPDM), ground calcium carbonate and furnace nano carbon black. Cure characteristics were carried out on oscillating disc rheometer. The crosslinking of rubber compounds was performed in a molding press. The compression set was assessed using the standard procedure. The morphology of the cryogenically fractured surface of samples with different content of paraffin oil was characterized by scanning electron microscopy (SEM). Mechanical properties and hardness were analyzed before and after the aging of obtained samples. Damping properties of prepared materialswere determined using bending mode. The loss tangent, $\tan \delta$, was used as a measure of vibration energy dissipation.
\end{abstract}

Keywords: Composites, Rubber, Elastomers, Hybrid materials, Filler, Mechanical spectroscopy.

\section{INTRODUCTION}

Elastomers are cross-linked polymers with a low modulus of elasticity and the capability to reverse large deformations at their service temperatures. Selecting proper network precursor for elastomers in sealant production requires an assessment of the environment in which it is anticipated to operate. The choice of the basic precursors in combination with adequate fillers, plasticizers, and curing agents are the key criteria for fabrication of the advanced sealant materials. Dynamics or pressure within a system may compel the use of complex sealing profiles or composite seal assemblies, consistedof multiple materials for different operating environments. Elastomers based on ethylenepropylene-diene monomer rubber (EPDM) have good compatibility with fireproof hydraulic fluids, ketones, alkalis, and unsatisfactory compatibility with most oils, gasoline, kerosene, aromatic and aliphatic hydrocarbons halogenated solvents and acids. This material has outstanding weather, heat, steam, ozone resistance and is very often used for microcellular products for example in cold-room doors, in the face seals of industrial respirators and also in automotive paint spray environments.

\footnotetext{
* Corresponding author: vojislav.jovanovic@pr.ac.rs

EPDM based on 5-ethylidene-2-norbornene (ENB) (Figure 1 ) is very sensitive to oxidation.

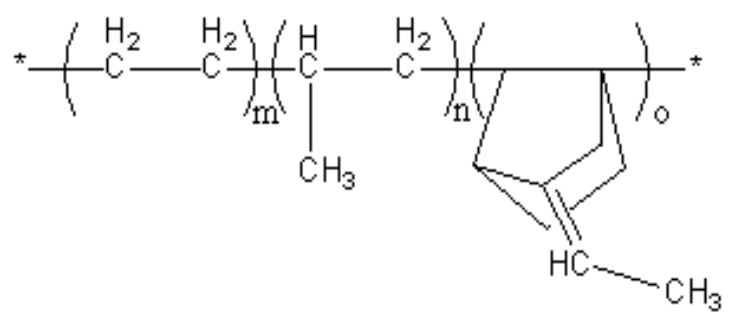

Figure 1. The structure of 5-ethylidene-2-norbornene.

The sensitivity of the ENB is very useful for subsequent crosslinking either by peroxide or sulfur. It is generally accepted that photo- or thermo-oxidation starts on the ENB part. (Jovanović et al., 2013). In the oil and gas industry, these materials are used in a wide range of applications (seals in shafts, pump pistons, flanges, rods, elastomeric belts for power transmission, and flexible hoses). Drilling sector makes an extensive use of elastomeric seals depending on drilling fluids. Because of increasingly severe environmental standards, the industry has developed environmentally friendly, synthetic drilling fluids as alternatives to conventional oil-based. These 
synthetic muds are in some uses incompatible with the conventional rubbers used in equipment. The issuesoccur for the subsea equipment at high pressure and cold temperatures (Akhtar et al., 2018). Rubber gaskets based on EPDM are an important component for a fuel cells fabrication because they work as sealing agent in the stack assembly. They work to provide the correct compression needed and act as a 'barrier' for potential fuel leaks; maximizing the highest possible efficiency. Longterm durability of the fuel cell stacks depends heavily on the functionality of the elastomeric gasket material. The compression set of multilayered elastomeric composites decreases with the increase of the layer number, indicating better sealing capacity and longer working life.

Rubber nanocomposites are heterogeneous systems where the significant volume fraction of macromolecular chains affected and strongly interacted by the nano-sized filler particles. Also, continuous break-up and rearrangement of particles take place due to the dynamic loads applied to the composite materials. It has been recognized that, for a given network precursor and curing system, the surface area and structure of filler, the hydrodynamic effect, and filler-filler and fillerpolymer interactions influence the dynamic properties of rubber (Allegra et al., 2008; Leblanc, 2002). In nanostructured materials properties of the interface, effect dominates the volume effect, while in materials with $\mu$-sized fillers the volume effect is dominating (Fröhlich et al., 2005). The rubber-filler interaction has been attributed to chemical bonds formation at the filler surface. (Jovanović et al., 2011)

Physical aging which occurs as the gradual process may greatly affect many properties in a way dependent on the aging temperature. Information about thermal properties is critical for development, processing, and application of elastomeric products. Heat aging stability is a hallmark of EPDM rubber and a requirement for the application in automotive, roofing and other industries. Retention of physical properties after accelerated heat aging is a typical specification for such longterm uses. For applications involving exposure to high temperature steam improved EPDM seals and O-rings are the best solution for submersible pumps. For subsea sealing equipment the main difficulties involves the low temperatures and high pressures. Seawater temperatures when combined with the high pressures could possibly cause the fail of subsurface equipment seals This is attributable to the increase of the elastomer glass transition temperature as extreme pressures decrease its free volume thereby reducing network chains mobility. Elastomeric elements on the rig such as the rotary hose or seals degrade at high temperatures. High-temperature compression set performance is influenced not only by the formation of new crosslinks during heating under compression but also by the inter-conversion of polysulfidic linkages present in the initial vulcanizates. Carbon black improves the aging resistance of elastomers due to its ability to absorb UV light, which otherwise would be absorbed by the polymer and initiate photo-oxidative reactions leading to deterioration. The interactions between rubber and filler particles are obviously initiated in the early stage of mixing but it is well known that the process is not instantaneous. Traditional methods of modification of the $\mathrm{Tg}$ value involves the use of copolymers, modified crosslinking agents, plasticizers, and fillers, blending of various polymers, grafting and formation of interpenetrating polymer networks. If elastomeric material is compressed over time, it loses its ability to return to its original thickness. This loss of resiliency may reduce the capability of elastomeric products to perform over a long time period. In rubber industry the compression set values are expressed as a percentage. The lower value is, the better is elastomeric material resistance on permanent deformation under a given temperature and deflection. In this applicative work the goal was to study the influence of active and inactive fillers on the properties of oilextended elastomeric hybrid materials based on EPDM rubber for sealnt fabrication.

\section{EXPERIMENTAL}

\section{Materials and methods}

As precursor was used ethylene-propylene diene monomer rubber (based on 5-ethylidene-2-norbornene) Vistalon 9500, produced by Exxon Mobil Chemical, France, 59.8\% wt ethylene content and $10.92 \%$ wt diene. Mooney viscosity was determinate under conditions: $\mathrm{ML}(1+4)$ at $\left(125^{\circ} \mathrm{C}\right)$ was 69.6 $\mathrm{Mu}$. Carbon black was the furnace black type, GPF N-660 Statex, produced by Columbian Chemical Company. The average particle diameter of carbon black was $70 \mathrm{~nm}$. As an inactive filler was used hydrophobic calcium carbonate, Kredafil 150S,. Relative density at $20{ }^{\circ} \mathrm{C}$ was 2.7 , particle size distribution 1-30 micron. Chalk loading was varied from 0 to 100 phr, carbon black content was 140 phr. Paraffinic oil (Texpar 460. Texaco) was used as extender with an low sulfur, nitrogen and aromatic hydrocarbon content (density at $15^{\circ} \mathrm{C}, \mathrm{kg} / \mathrm{l} 0.9012$ $\mathrm{kg} / \mathrm{l}$, Kin viscosity at $40^{\circ} \mathrm{C}, 473.1 \mathrm{~mm}^{2} / \mathrm{s}$ ). It is produced by modern technology for fabrication from the premium grades of mineral oils. Paraffinic process oils with high flash point and high viscosity are better for shelf life of the rubber product. Because paraffinic furfural extract has higher viscosity and paraffinic content are preferred for achieving high retention of properties after thermal ageing in applications like heat resistant sealants, conveyor belts and steam hoses.

Achieving of fast curing reaction was possible using accelerators (thiazoles, mercaptobenzothiazole, dibenzothiazyl disulfide). For compound preparation the rubbers were separately premasticated for about $1 \mathrm{~min}$ each, keeping a tight nip gap $(0.8$ $\mathrm{mm}$ ), and subsequently blended for 3 minutes. The compounds were prepared on a laboratory electrically heated rubber mill to enable the homogeneous mixture. The mixing time was 20 
minutes. After mixing, the Mooney viscosity (ML1+4 at $100{ }^{\circ} \mathrm{C}$ ) of the compounds was measured by a Mooney viscometer. The sheeted compound was conditioned at $23 \pm 2{ }^{\circ} \mathrm{C}$ during $24 \mathrm{~h}$ prior to cure assessment using the oscillating disc rheometer (Monsanto R-100) at $180 \pm 1^{\circ} \mathrm{C}$. The compounds were cured by sulfur at $160^{\circ} \mathrm{C}$. The curing characteristics: $\mathrm{Ml}$ (minimum torque), Mh (maximum torque), $\mathrm{t}_{\mathrm{c} 90}$ (optimum cure time), $\mathrm{t}_{\mathrm{s} 2}$ (scorch time) were registered and curing rate index was calculated (Marković et al., 2009). To perform a systematic study, elastomers without and with active and inactive filler were prepared and crosslinked under similar experimental conditions.

For mechanical properties determination, all test specimens were compression molded at $160{ }^{\circ} \mathrm{C}$ during the earlier determined respective optimum cure time $\left(\mathrm{t}_{\mathrm{c} 90}\right)$. The dumbbell samples were cut from a $2 \mathrm{~mm}$ thick molded sheet. The mechanical properties were obtained from stress/strain measurements by the Tensile tester (Karl Frank, Germany) according to ASTM D412-98a (before and after aging at $70{ }^{\circ} \mathrm{C}$ for $46 \mathrm{~h}$ in air). The crosshead speed for the tensile test was 500 $\mathrm{mm} / \mathrm{min}$. The retained percentage value of tensile strength and elongation at break were calculated. The hardness of the elastomer samples was determined by the standard method using an indentation hardness tester (Shore A type). Samples with flat surface were cut for hardness test. The compression set was assessed using the standard compression set measurement according ASTM D395. The dynamic mechanical spectra of some prepared materials were obtained using a dynamic mechanical thermal analyzer (DMTA 2980, TA Instruments). All samples were analyzed by bending mode over a frequency from 1 to $200 \mathrm{~Hz}$ and with a constant strain $0.1 \%$. The measurement was performed under a nitrogen (flow rate $20 \mathrm{ml} / \mathrm{min}$ ). The maximum in the plot of $\tan \delta$ versus temperature was taken as the glass to rubber transition, Tg. A JEOL scanning electron microscope SEM was used to perform morphology of oil extended elastomeric materials. Each sample was fractured cryogenically and submitted to gold sputtering before analysis.

\section{RESULTS AND DISCUSSION}

\section{Curing characteristics}

For compounds, type and content of filler affect the cure characteristics. Lots of functional groups such as hydroxyl, carboxyl, lactone, pyrone, ketone, quinone, and phenol exist on the carbon black surface but the amount is small. The effect of chalk loading on cure characteristics for samples with $140 \mathrm{phr}$ carbon black is shown in Figure 2. The correlation curves for cure rate index and filler content are given in the Figure 3. The cure rate of filled compound became faster as the chalk content increased. Retention of physical properties after accelerated heat aging is a typical for the long term use of elastomers.

The used plasticizer for elastomeric hybrid materials based on EPDM as network precursor was parrafinic process oil thus it was very effective because this process oil has the advantage to be compatible with this network precursor (both are non-polar). In practice, this means that there the sweating is prevented even at temperature interval extremes from -40 to $+80{ }^{\circ} \mathrm{C}$. In Table 1 are given mechanical properties and harness of prepared hybrid material before aging (BA) and after aging (AA).

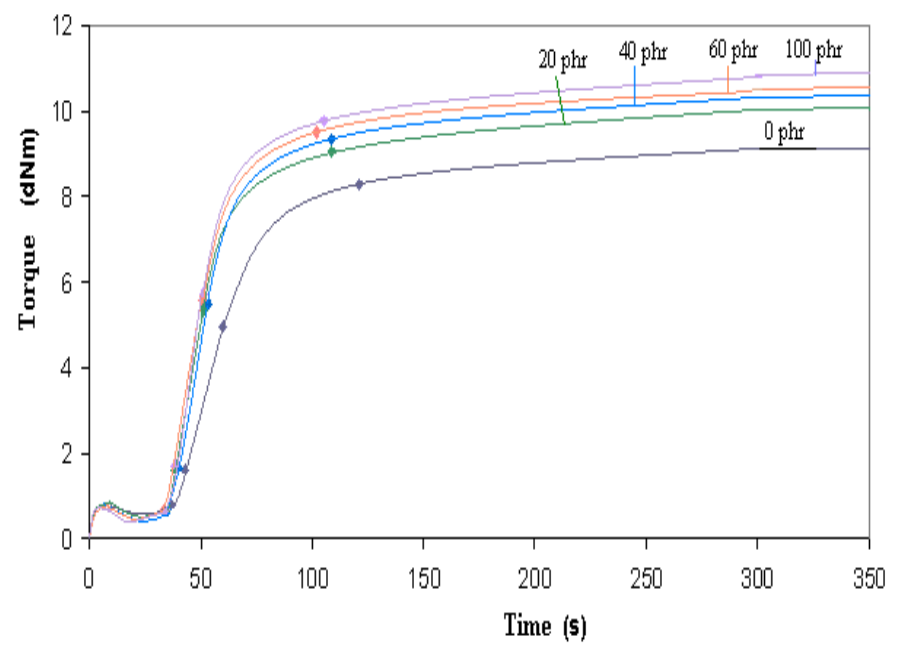

Figure 2. Torque-time dependence for compounds with $140 \mathrm{phr}$ carbon black and different chalk content during curing at $160{ }^{\circ} \mathrm{C}$.

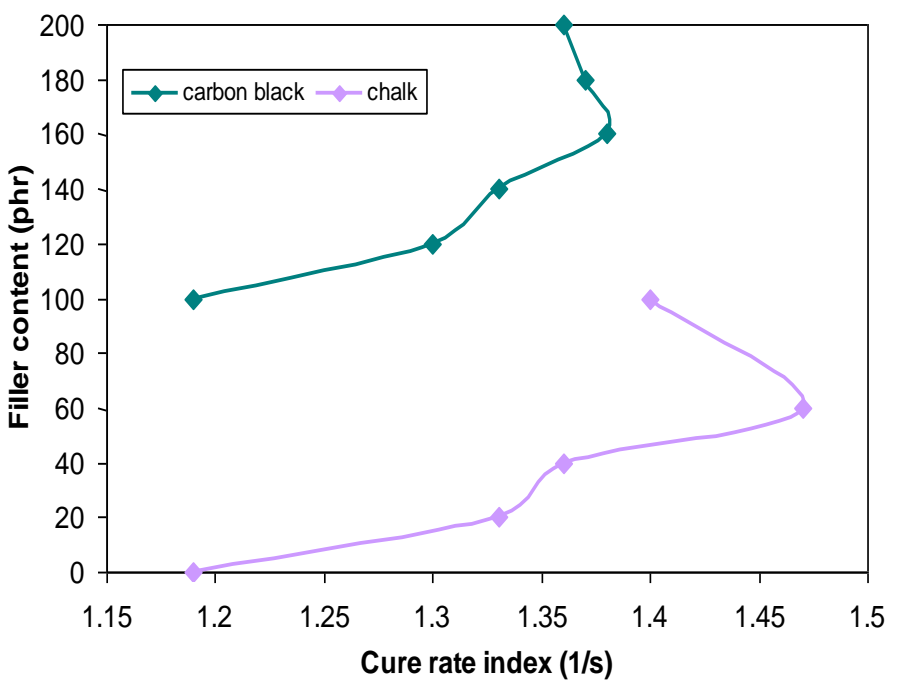

Figure 3. Obtained correlation of curing rate index and filler content for oil-extended elastomeric hybrid materials.

\section{Mechanical properties of hybrid elastomeric materials}

It was estimated that for the all samples hardness was increased with the increase of chalk content. As can beobserved, for all samples the hardness was increased with increased filler loadings. The tensile strength decreased with increasing filler loading, whereas elongation at break was increasing at low chalk content, but after what was decreasing. Compression set testing measures the ability of rubber to return to its original thickness after prolonged compressive stresses at a given deflection. 
Vibrations often have influence on undesirable motions and dynamic stresses, which could lead to the structure failure and other unwanted consequences. The values of compression set are also given in Table 1. From these results, it can be seen that the compression set values for $25 \%$ of deformation are low and adequate for sealant application.

Table 1. Mechanical properties of oil extended elastomer samples based on $140 \mathrm{phr}$ of carbon black and different content of chalk, before (BA) and after aging (AA).

\begin{tabular}{|c|c|c|c|c|c|c|}
\hline \multirow{2}{*}{ Sample } & \multicolumn{2}{|c|}{$\begin{array}{c}\text { Hardness } \\
\text { (Sh A) }\end{array}$} & \multicolumn{2}{c|}{$\begin{array}{c}\text { Tensile } \\
\text { strength } \\
\left(\mathrm{N} / \mathrm{mm}^{2}\right)\end{array}$} & \multicolumn{2}{c|}{$\begin{array}{c}\text { Compression } \\
\text { set }(\%)\end{array}$} \\
\cline { 2 - 8 } & BA & AA & BA & AA & $\begin{array}{l}\text { for } \\
25 \%\end{array}$ & $\begin{array}{l}\text { for } \\
50 \%\end{array}$ \\
\hline EPDM/CB140/K0 & 57.7 & 58.3 & 9.64 & 9.95 & 9.2 & 33.8 \\
\hline EPDM/CB140/K20 & 59.7 & 59.7 & 9.05 & 8.82 & 6.2 & 27.7 \\
\hline EPDM/CB140/K40 & 61.0 & 61.7 & 8.25 & 8.17 & 9.2 & 26.2 \\
\hline EPDM/CB140/K60 & 62.0 & 63.0 & 7.36 & 7.39 & 9.2 & 27.7 \\
\hline EPDM/CB140/K100 & 63.0 & 63.3 & 6.43 & 6.36 & 9.2 & 33.8 \\
\hline
\end{tabular}

The dynamic-mechanical behavior of hybrid materials

For the investigation of the low temperature properties, thermal analysis method DMA was applied to assess the region of the glass rubber transition process. The response of elastomers to an applied energy can be energy storage or energy dissipation. For sealing materials, the elastic component is most important. An applied stress induces a strain which forms contact stress or sealing force. As the macromolecular chains rearrange to reduce this stored force, a loss of sealing force occurs. These materials have elastic and damping behaviour because they are viscoelastic materials. Dynamic losses are associated with specific mechanisms of molecular motion in cross-linked materials. The damping (the energy loss per cycle) can be measured from the tangent of the phase angle. The compression set is very important characteristic of elastomeric sealing materials as spontaneous stress release during application due to the internal pressure changes or external forces variations. During heating, the storage modulus shows the typical decrease during glass transition region which is associated with the peaks of loss modulus and loss tangent $\tan \delta$.

In this study, the $\tan \delta$, was used for assessment of the hybrid materials damping properties. The storage modulus drops by several orders with increasing temperature, while the loss modulus and $\tan \delta$ show a characteristic peak. The chemical reaction between the filler and elastomer and occlusion of the rubber macromolecules within the pores of the filler particles affect on mechanical response and final morphology under a given set of conditions of temperature and filler loading level. The particles are expected to contribute to the increase of phase angle $(\tan \delta)$ in the rubbery phase of material beyond the glass transition temperature. The loss tangent $(\tan \delta)$, defined by the ratio of loss modulus $\left(\mathrm{E}^{\prime \prime}\right)$ to storage modulus $\left(\mathrm{E}^{\prime}\right)$, can be a measure of the vibration energy dissipation. High-performance damping materials should have a high value of arbitrary defined loss factor $(\tan \delta>0.3)$ over a broad temperature range. Figure 4 displays the dependence of loss tangent on the temperature at different frequencies for oil-extended sample with $100 \mathrm{phr}$ chalk.

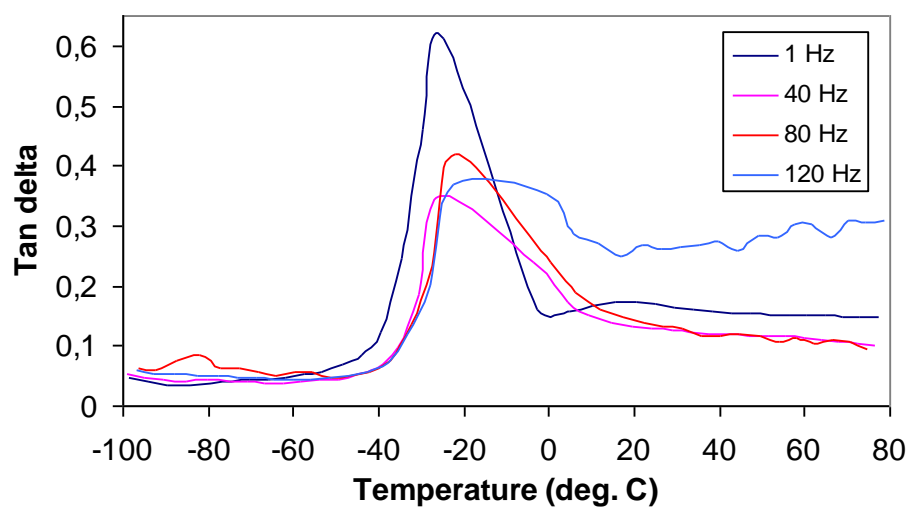

Figure 4. Dependence of loss tangent on the temperature at different frequencies for oil-extended elastomeric hybrid materials with 140 phr furnace carbon black and 100 phr chalk.

It was estimated that chalk addition causes better damping properties under high frequencies in comparison with samples without chalk. The temperature range with $\tan \delta>0.3$ was used to assess the damping capacity for the sample with 140 phr carbon black and different chalk content, as some kind of arbitrary criteria for practical comparison. In the Table 2 are given data for determined $\mathrm{Tg}$ values and arbitrary damping capacity.

Table 2. Damping properties of elastomeric materials filled with $140 \mathrm{phr}$ of carbon black and different content of chalk.

\begin{tabular}{|c|c|c|c|c|}
\hline \multirow{2}{*}{ Sample } & \multicolumn{3}{|c|}{$\begin{array}{c}\text { Damping capacity as } \\
\text { temperature interval for } \\
\text { tan }>0.3\end{array}$} & \\
& \multicolumn{3}{|c|}{$\mathrm{Tg}$} \\
& $\left({ }^{\circ} \mathrm{C}\right)$ \\
\cline { 2 - 4 } & $1 \mathrm{~Hz}$ & $40 \mathrm{~Hz}$ & $80 \mathrm{~Hz}$ & \\
\hline EPDM/CB140/K0 & - & - & 22.16 & -32.50 \\
\hline EPDM/CB140/K40 & 15.83 & 8.33 & 8.33 & -33.33 \\
\hline EPDM/CB140/K60 & 15.83 & 10.42 & 10.83 & -33.75 \\
\hline EPDM/CB140/K100 & 24.17 & 19.58 & 15.83 & -26.67 \\
\hline
\end{tabular}

The $\mathrm{Tg}$ values are determined as the position of $\tan \delta$ maximum obtained at $1 \mathrm{~Hz}$. It was assessed that in glassy region state below about $-26^{\circ} \mathrm{C}$, the hybrid materials have a high storage modulus and in the rubberlike state at temperatures above $-26{ }^{\circ} \mathrm{C}$ the modulus is rather low. The addition of filler particles provides high strength and modulus, whereas the 
damping peak height is decreased sharply while the damping peak position is shifted. The expected frequency dependence of the mechanical properties becomes confirmed by the shift of the glass transition region with enlarging the frequency. This is important to know for the dynamic seals devices that may be stressed at high frequencies or during short times during elastomeric material exploitation. Figure 5 displays the correlation of storage modulus assessed at different frequencies of deformation at $25^{\circ} \mathrm{C}$ and hardness for prepared elastomeric hybrid materials.

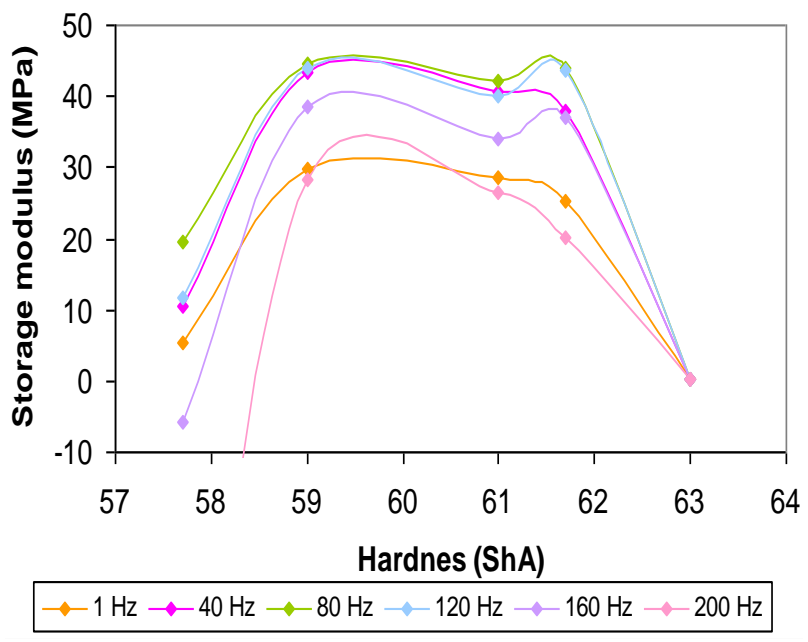

Figure 5. Correlation of storage modulus obtained at different frequencies of dynamic deformation at $25^{\circ} \mathrm{C}$ with hardness for prepared elastomeric hybrid materials.

\section{The morphology of oil-extended samples}

The morphology of the cryogenically fractured surface of samples with different content of paraffin oil was characterized by scanning electron microscopy. It can be stated that the oil influenced the morphology significant.

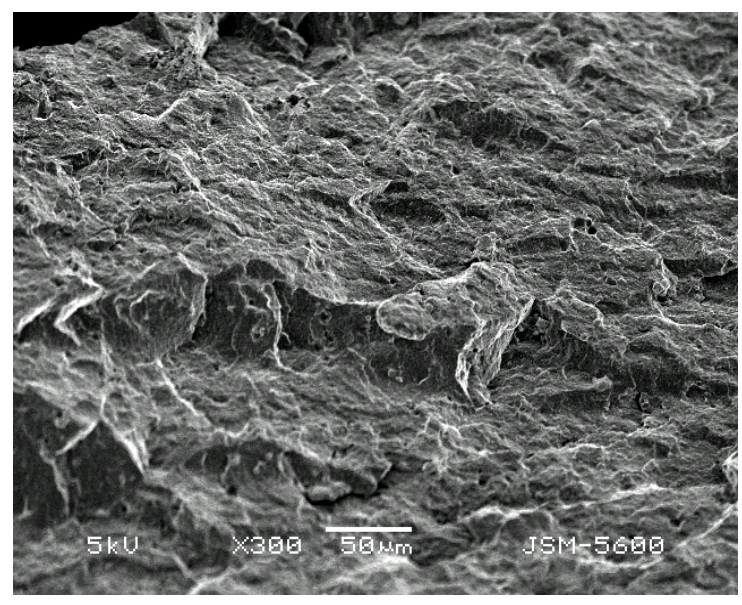

Figure 6. SEM micrograph of elastomers with 140 phr carbon black, 20 phr chalk and 73 phr paraffinic oil (X300).

In the Figures 6-8, are shown SEM micrographs of hybrid materials based on $140 \mathrm{phr}$ carbon black and $20 \mathrm{phr}$ chalk with different content of paraffin oil. As expected, it was noticed, that a higher concentration of paraffinic oil influenced the materials morphology significant. The advantage is to dilute elastomers with less expensive oil and also to improve material processability. This enables the use of higher-molecular-weight network precursors for hybrid materials preparation.

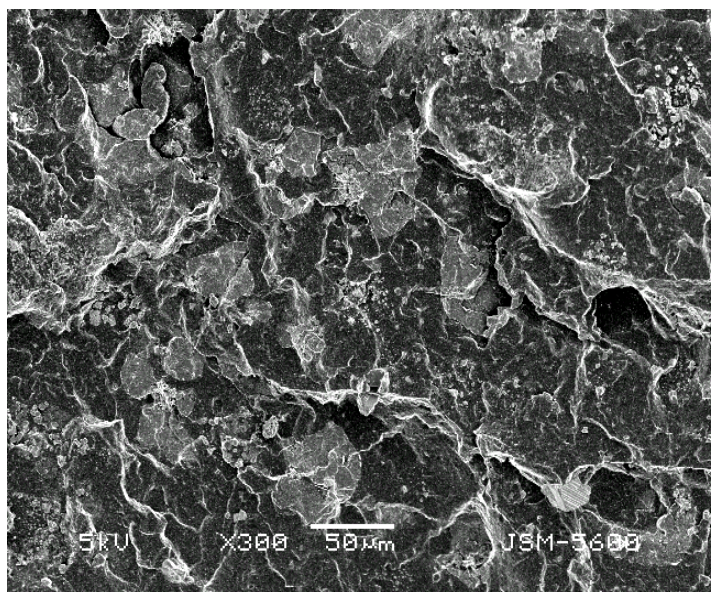

Figure 7. SEM micrograph of elastomers with 140 phr carbon black, 20 phr chalk and 98 phr paraffinic oil (X300).

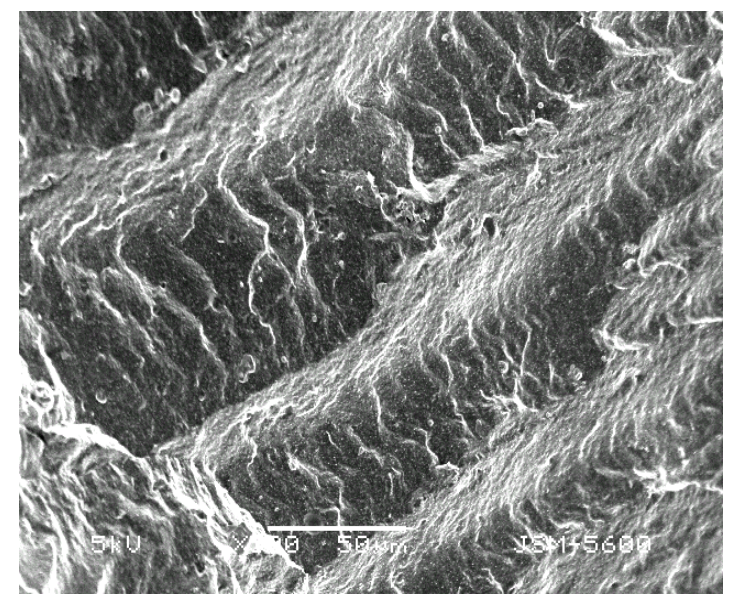

Figure 8. SEM micrograph of elastomers with $140 \mathrm{phr}$ carbon black, 20 phr chalk and 118 phr paraffinic oil (X500).

\section{CONCLUSIONS}

The present study was undertaken to give a detailed analysis of the influence of active filler carbon black and inactive ground calcium carbonate on compression set values and dynamical-mechanical properties of elastomeric hybrid materials for sealant fabrication. The used paraffinic process oils with high viscosity were adequate for achieving high properties retention of prepared materials after thermal ageing. The compression set is important as spontaneous stress release of the seal and is simulated what could occur due to the external forces or internal pressure changes during sealant exploitation. It was estimated that values of the compression set obtained for $25 \%$ of 
deformation are excellent for application. It was assessed that the chalk addition in a small amount, has a positive contribution to modulus and does not change tensile strength. The estimated higher temperature maximum of $\tan \delta$ is due to the adsorbed hard rubber around the carbon black aggregates. As expected, it was assessed from SEM micrograph that the content of paraffinic oil influenced the hybrid elastomeric materials morphology. The enhanced thermal stability for filled samples is evidenced from the tensile strength however, reductions of some mechanical properties could be noticed .

\section{ACKNOWLEDGMENTS}

Financial support for this study was granted by the Ministry of Educations, Science and Technological Development of the Republic of Serbia (Projects Number III 45022).

\section{REFERENCES}

Allegra, G., Raos, G., \& Vacatello, M. 2008. Theories and simulations of polymer-based nanocomposites: From chain statistics to reinforcement. Progress in Polymer Science, 33(7), pp. 683-731. doi:10.1016/j.progpolymsci.2008.02.003

Fröhlich, J., Niedermeier, W., \& Luginsland, H. 2005. The effect of filler-filler and filler-elastomer interaction on rubber reinforcement. Composites Part A: Applied Science and Manufacturing, 36(4), pp. 449-460. doi:10.1016/j.compositesa.2004.10.004

Jovanović, V., Samaržija-Jovanović, S., Marković, G., Marinović-Cincović, M., \& Budinski-Simendić, J. 2011. Mechanical and Morphological Properties Rubber Blends Reinforced with Nanofillers. Kautschuk Gummi Kunststoffe, 9, pp. 52-56.

Jovanović, V., Samaržija-Jovanović, S., Budinski-Simendić, J., Marković, G., \& Marinović-Cincović, M. 2013. Composites based on carbon black reinforced NBR/EPDM rubber blends. Composites Part B: Engineering, 45(1), pp. 333-340. doi:10.1016/j.compositesb.2012.05.020

Leblanc, J. 2002. Rubber-filler interactions and rheological properties in filled compounds. Progress in Polymer Science, 27(4), pp. 627-687. doi:10.1016/s0079-6700(01)00040-5

Marković, G., Dević, S., Marinović-Cincović, M., \& BudinskiSimendić, J. 2009. Influence of carbon black on reinforcement. Kautschuk Gummi Kunststoffe, 62(6) pp. 299-305. 